$16^{\circ}$ USIHC - Congresso Internacional de Ergonomia e Usabilidade de USIHC Interfaces Humano Computador

\title{
DESIGN SOCIAL - ESTUDO DE CASO SOBRE O DESENVOLVIMENTO DE UM GUINDASTE PARA SUSPENSÃO DE BAGS EM UMA ASSOCIAÇÃO DE RECICLAGEM
}

\section{SOCIAL DESIGN-CASE STUDY ON THE DEVELOPMENT OF A CRANE FOR BAGS IN A RECYCLING ASSOCIATION}

\author{
Anderson Anselmi Rossetti \\ Lucas Augusto Proti \\ Fatec Jahu \\ Andenrsonitajau@hotmail.com \\ Fatec Jahu \\ Lucas_proti412@hotmail.com
}

Palavras-chave: Design, Ergonomia, Guindaste.

\begin{abstract}
A Associação Recicla Jaú tem por missão a coleta e separação de sucata no Município de Jaú/SP. Os associados alternam nas funções de seleção e movimentação dos Bags (grandes bolsas), essa movimentação pode oferecer riscos à saúde deles. Foi identificada a necessidade de melhorar as condições de trabalho na Associação. O objetivo desse projeto foi desenvolver um guindaste, ergonomicamente adequado, para mover os Bags do chão ao interior da caçamba. A metodologia utilizada foi a Pesquisa Tecnológica, com a realização de visita técnica à Associação no intuito de observar os trabalhadores e levantar os problemas enfrentados, e contribuir com ideias para elaboração de um produto que suspendesse os Bags, carregados de sucatas, do chão até o interior da caçamba, na qual se armazenam as sucatas de ferro até a sua retirada. Após a confecção do guindaste, obteve-se sucesso no transporte dos Bags, pois o equipamento suportou a carga de $100 \mathrm{~kg}$.
\end{abstract}

Keywords: Design, Ergonomics, Crane.

The Association Recycles Jau's mission is the collection and separation of scrap in the municipality of Jau/SP. members alternate in the roles of selection and movement of the Bags (big bags), this movement can offer their health risks. It was identified the need to improve working conditions in the Association. The goal of this project was to develop a crane, ergonomically appropriate, to move the Bags from the ground to the inside of the bucket. The methodology used was the technological research, with the completion of a technical visit to the Association in order to observe the workers and raise the problems faced, and contribute with ideas for development of a product that suspend the Bags, loaded with scrap from the floor up to the inside of the bucket, in which stored the scrap until your withdrawal. After the making of the crane, success was achieved in the transport of Bags, because the equipment bore the load of $100 \mathrm{~kg}$. 


\section{$16^{\circ}$ \\ ERGODESIGN USIHC CINAHPA}

\section{Introdução}

Os alunos do Curso de Tecnologia da Gestão da Produção Industrial da Fatec Jahu, por meio de uma pareceria realizada com a Associação Recicla Jaú (Recicla), iniciaram um projeto no ano de 2015, com a finalidade de proporcionar melhorias nas tarefas realizadas pelos colaboradores da referida Associação.

Foram levantados alguns problemas relacionados às tarefas e atividades que os colaboradores desempenham na Associação, dentre eles, problemas relacionados à ergonomia no ambiente de trabalho, os quais podem oferecer riscos físicos aos trabalhadores devido aos esforços excessivos na realização das atividades. Nas plataformas improvisadas havia a possibilidade de riscos de acidentes para os operários, pois nelas são efetuadas as suspensões dos Bags - sacos onde se colocam produtos reciclados (metais) medem até 3 metros de altura e aproximadamente até 100 quilogramas $(\mathrm{kg})$ de peso.

O projeto propõe um único braço giratório que abrange todo raio de atuação, com giro de $360^{\circ}$, fabricado com viga, tubo perfilado montado em uma coluna, com base fixa em uma caçamba, de forma que consiga transportar os Bags do chão ao interior da caçamba.

\subsection{Objetivos}

Desenvolver um braço mecânico (guindaste) para mover os Bags do chão ao interior da caçamba na Associação Recicla Jaú a partir de parâmetros da ergonomia.

\subsection{Referencial Teórico}

Para fundamentar o tema da pesquisa realizada, essa seção apresenta os principais conceitos, envolvendo ergonomia e projeto de produto.

\section{Ergonomia}

A ergonomia pode ser aplicada desde as etapas iniciais do projeto de uma máquina, sistema, ambiente ou local de trabalho. Em si as etapas $16^{\circ}$ Ergodesign - Congresso Internacional de Ergonomia e Usabilidade de Interfaces Humano Tecnológica: Produto, Informações Ambientes Construídos e Transporte

$16^{\circ}$ USIHC - Congresso Internacional de Ergonomia e Usabilidade de Interfaces Humano Computador

CINAHPA | 2017 - Congresso Internacional de Ambientes Hipermídia para Aprendizagem.

devem sempre incluir o ser humano como um de seus componentes e cada um desses operadores deve ser considerado conjuntamente com as características ou restrição das partes mecânicas, sistêmicas ou ambientais, para se ajustarem corretamente umas às outras (IIDA, 2005). A ergonomia de concepção é uma interferência mais ampla no desenvolvimento no projeto - da planta, instalações de equipamentos, organização da linha de produção e formação de pessoal, assim com bom planejamento favorece a chance de sucesso no uso (usabilidade, operacionalização, etc.).

No desenvolvimento de produto, entende-se que o design se trata de uma atividade multidisciplinar voltada a projetar produtos dotados de atributos estéticos, simbólicos e funcionais, os quais são os seus parâmetros. Elevá-lo ao patamar estratégico da empresa, hoje, deve ser uma regra, porque o sucesso é o somatório de diversas áreas distintas No setor organizacional pode-se enfatizar sua aplicação em vários setores dos sistemas de produção como, por exemplo: i) nos objetivos de racionalização do trabalho para o aumento de produtividade; ii) na segurança, visando à prevenção dos acidentes de trabalho; iii) nas soluções ergonômicas, visando à eliminação ou minimização das doenças; e iv) nos constrangimentos profissionais causados por objetos mal projetados. Ainda é possível observar exemplos nas pesquisas antropométricas com a população brasileira, no avanço da engenharia cognitiva, na ergonomia voltada para a informática, na psicologia e na medicina do trabalho, com ênfase, sobretudo, na aplicação dos conhecimentos ergonômicos, na organização de linhas de produção, ambientes e postos de trabalho, correção de equipamentos de uso individual e geral, entre outros (GOMES FILHO, 2010).

Existe no trabalho, em relação ao levantamento de pesos, sendo classificados em dois tipos levantamento um deles refere-se ao levantamento esporádico de cargas, que está relacionado com a capacidade muscular. O outro tipo é levantamento repetitivo, com levantamento de cargas em que se deve considerara de longa duração do trabalho. Nesse caso, o fator limitativo será a capacidade enérgica do trabalhador e a fadiga física, sendo que
Realização:

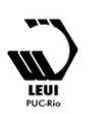




\section{$16^{\circ}$ \\ ERGODESIGN USIHC CINAHPA}

a capacidade de carga máxima, possível de ser carregada, varia de uma pessoa para outra, de acordo como é realizada a utilização da musculatura das pernas, braços ou dorso (IIDA, 2005).

O estudo do posicionamento relativo de partes do corpo, como cabeça, troncos e membros é importante para realização do trabalho sem desconforto e estresse. (IIDA, 2005).

\section{Projeto}

De acordo (Baxter 1998, p. 174)

...[o projeto conceitual tem o objetivo de produzir princípios de projeto para o novo produto. Ele deve ser suficiente para satisfazer as exigências do consumidor e diferenciar o novo produto de outros produtos existentes no mercado. Especificamente, o projeto conceitual deve mostrar como novo produto será feito para atingir os benefícios básicos. Portanto, para projeto conceitual, é necessário que beneficie básico esteja bem definido e se tenha uma boa compreensão das necessidades do consumidor e dos produtos concorrentes.]

Para (Dijon de Moraes 2010, p. 220)

...[a aplicação do metaprojeto é, portanto, uma síntese do esforço empreendido na decomposição e decodificação dos cenários possíveis, de modo a incutir maior valor e melhor qualidade que venham a resultar em benefícios para os usuários, avanços da cultura produtiva e enriquecimentos para cultura do design, este, aqui entendido como o campo de conhecimento estratégico e avançado dentro do complexo cenário mundial estabelecido.]

As etapas de projeto, segundo (Baxter, 1998), são:

\section{Análise do problema}

(BAXTER, 1998). A análise do problema serve para conhecer as causas básicas e assim fixar as suas metas e fronteiras. Começa com a formulação do problema observando todas as características para se tiver estudo detalhado do caso. $16^{\circ}$ Ergodesign - Congresso Internacional de Ergonomia e Usabilidade de Interfaces Humano Tecnológica: Produto, Informações Ambientes Construídos e Transporte

$16^{\circ}$ USIHC - Congresso Internacional de Ergonomia e Usabilidade de Interfaces Humano Computador

CINAHPA | 2017 - Congresso Internacional de Ambientes Hipermídia para Aprendizagem.

\section{Geração de ideias}

(BAXTER, 1998). A geração de ideias é a alma de criação, vimos que inspiração criatividade pode resultar do pensamento e juntando-se as ideias que antes não estavam relacionadas entre si.

\section{Seleção de ideias}

Segundo Baxter (1998) a seleção de ideias é um processo mais sistemático, disciplinado e rigoroso que os procedimentos de geração das ideias. Tem como finalidade identificar, no meio das muitas ideias geradas, aquela que melhor soluciona-se o problema proposto e seleção também exige criatividade para combinar e adaptaras ideias às necessidades de solução.

\section{Planejamento}

O planejamento do produto se destina a identificação de uma oportunidade, pesquisa de produto, analise dos produtos concorrentes e não fugindo junto as elaboração de ideias proposta de novo produto. A elaboração do planejamento reuniu todas as especificações e produto similares de acordo com seleção de ideias (BAXTER, 1998).

\section{Prototipagem}

(BAXTER, 1998). O projeto detalhado com resultados da configuração, determinando como produto será produzido. Essa etapa é muito importante, pois através dele se caracteriza estética de produto, funcionalidade e aprimoramento do produto antes de ser produzido.

\section{Teste}

(BAXTER, 1998). Esse tipo de análise pode levar a diversas funcionamento praticas do produto. Em primeiro lugar, as falha estão relacionadas com o tipo de uso do produto e segundo, a analise pode prever determinadas falhas, mas que não terão forte impacto sobre consumidor.

No presente estudo o projeto desenvolvido foi um guindaste (braço mecânico) com a finalidade de auxiliar os colaboradores de uma Associação de material reciclável. 


\section{$16^{\circ}$ \\ ERGODESIGN USIHC CINAHPA}

\section{Metodologia}

Foi realizada uma Pesquisa Tecnológica para o desenvolvimento de um guindaste a partir de parâmetros ergonômicos. Segundo Cupani (2006, p.356), "constitui-se em um sistema adaptado ao ambiente em função determinado proposito humano, um objeto (artefato) com propriedades desejadas, idealizado e fabricado conforme o desenho e o projeto (design)". Pesquisa tecnológica é a aplicação de conhecimentos técnicos e científicos e sua transformação em ferramentas em processos de materiais e procedimentos a serem aplicados.

$\mathrm{O}$ produto foi desenvolvido a partir das etapas sugeridas por Baxter (2008).

\subsection{Resultados e Discussões}

Segundo Baxter (2000), a ergonomia tem por objetivo entender as relações entre as pessoas, os artefatos e o meio-ambiente, usando conhecimentos de anatomia, fisiologia e psicologia, direcionando isto ao projeto de objetos. Por fim, a representação das soluções pode ser feita por meio de esquemas, croquis ou desenhos.

A partir da identificação da necessidade da Recicla, foi elaborado um projeto para desenvolver o braço mecânico, com o intuito de melhorar o processo de transporte dos bags do chão para o interior da caçamba, levando em consideração os princípios da ergonomia, de forma que o transporte possa acontecer de forma segura, fácil e rápida.

\subsection{Projeto de Produto}

\subsubsection{Equipamentos}

Ao longo do projeto foram utilizados equipamentos tais como: Serra policorte; Lixadeira manual; Solda elétrica; e Furadeira manual.

\subsubsection{Materiais}

Foram utilizados diversos materiais para que fosse possível desenvolver o produto em questão, entre eles: Vergalhão de aço SAE 1020 redondo diâmetro 32 milímetros (mm); Chapa de aço SAE $16^{\circ}$ Ergodesign - Congresso Internacional de Ergonomia e Usabilidade de Interfaces Humano Tecnológica: Produto, Informações Ambientes Construídos e Transporte

$16^{\circ}$ USIHC - Congresso Internacional de Ergonomia e Usabilidade de Interfaces Humano Computador

CINAHPA | 2017 - Congresso Internacional de Ambientes Hipermídia para Aprendizagem.

$1020 \mathrm{U} 115 \mathrm{mmx} 45 \mathrm{~mm}$; Eletrodo revestido diâmetro $6 \mathrm{~mm} \times 265 \mathrm{~mm}$; Parafuso sextavado de aço rosca $12 \mathrm{~mm} \times 85 \mathrm{~mm}$; Macho rosca $12 \mathrm{mmmx} 1,5 \mathrm{p}$; e Disco de desbaste BNA 12178 x 1,6 x 22,2mm.

Utilização de 1,20 metros (m) de vergalhão, para a estrutura da parte superior do braço e sua articulação de raio, sendo também soldada na parte superior uma chapa em forma de "U", como estrutura para enganchar o Bag. O eletrodo foi utilizado para união das chapas com o vergalhão e, depois, realizada a soldagem da estrutura base. Como forma de fixação da base foi necessários, de acordo com projeto, três parafusos de apoio que, para essa elaboração, foram realizadas roscas com ferramenta "macho", de modo que pudessem ser introduzidas na chapa base. Por fim, foi utilizado o disco de corte, para preparar a matéria-prima de acordo com o projeto.

\subsubsection{Análise do Problema}

A Associação Recicla Jaú apresentava um problema em relação ao transporte de sucata que era depositada em caçamba. Os trabalhadores por meio de improvisamente elaborou uma plataforma feita de resto de sucatas como: caixas de chapa de aço, latas de aço, corpo externo da máquina de lavar (sucata), entre outras. Na operação, havia dois trabalhadores que ficavam na plataforma e outros dois que eram encarregados de entregar os bags, suspendendo e entregando aos outros trabalhadores. A realização das atividades necessitava de esforço excessivo por parte dos trabalhadores, tendo acarretamento de lesões nas colunas dos trabalhadores e doenças que prejudicaram futuramente.

Após a análise do problema, foi efetuado o estudo de produtos similares, para que fosse possível compreender as possibilidades de transporte dos materiais. Uma delas, por suspensão, permitiu extrair ideias para o desenvolvimento do equipamento de suspensão.

\subsubsection{Análise do produto e geração de ideias}

Depois de realizada a análise dos similares, foi possível identificar a dimensão padrão. De acordo
Realização:

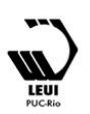




\section{$16^{\circ}$ \\ ERGODESIGN USIHC CINAHPA}

sendo as medidas do braço superior $1,20 \mathrm{~m}$ a 4,00 $\mathrm{m}$ e a capacidade de peso tolerado da estrutura de $200 \mathrm{~kg}$ a $800 \mathrm{~kg}$ e os formatos disponíveis no mercado guindastes, com uma coluna na vertical e haste na horizontal. Coluna de apoio de $1,50 \mathrm{~m}$ a $8,00 \mathrm{~m}$ de altura e diâmetros de $30 \mathrm{~mm}$ a $620 \mathrm{~mm}$, tendo uma espessura de $4,76 \mathrm{~mm}$ a $9,52 \mathrm{~mm}$ suficientemente forte para suportar cargas pesadas. Foi observado que havia reforços na base para tornar o produto mais resistente e evitar problemas que poderiam abalar sua estrutura. Na estrutura superior havia encaixe entre a coluna central do braço e a parte superior do produto. Assim, é possível aproveitar o raio e manter o eixo de movimentação no lugar.

\subsubsection{Seleção de ideias}

Por meio da seleção de ideias foi possível desenvolver um braço mecânico que tinha como características sua base de apoio fixada na estrutura da caçamba e que tenha uma altura 1, 50 $\mathrm{m}$, com diâmetro de $32 \mathrm{~mm}$ e comprimento do braço $1,10 \mathrm{~m}$ suficiente para suspender o bag e movimenta-lo até parte interior e ser depositado. Pensando em durabilidade, fácil instalação, simplicidade na operação, baixo custo para ser feito, qualidade em sua matéria- prima, sendo que esse produto levantará cargas excessivas de 100 $\mathrm{kg}$.

\subsubsection{Detalhamento do Projeto:}

Foi desenvolvido um braço mecânico de uma Haste (bandeira) 1,50 m, com articulação em sua parte superior $1,10 \mathrm{~m}$, promovendo, assim, $\mathrm{o}$ movimento giratório e facilitando a mobilidade dos bags. Sua viga em formato de "U" foi colocada no projeto visando resistência ao peso, sendo que sua estrutura central continha um cano para fornecer resistência à deformação do produto. $\mathrm{O}$ equipamento proporciona ao seu usuário a praticidade e conforto, visando diminuindo o esforço físico no transporte de cargas pesadas.

\subsubsection{Prototipagem:}

No desenvolvimento do protótipo foram utilizados canos de PVC com medidas de $1 / 2$ polegada, onde a $16^{\circ}$ Ergodesign - Congresso Internacional de Ergonomia e Usabilidade de Interfaces Humano Tecnológica: Produto, Informações Ambientes Construídos e Transporte

$16^{\circ}$ USIHC - Congresso Internacional de Ergonomia e Usabilidade de Interfaces Humano Computador

CINAHPA | 2017 - Congresso Internacional de Ambientes Hipermídia para Aprendizagem.

ideia do produto pode ser visualizada antes de todo processo de fabricação do produto.

\subsubsection{Elaboração do Projeto:}

\section{Montagem}

Nesse processo todos componentes do produto foram cortados em suas respectivas medidas e, em seguida, colocadas no lugar para sua união.

\section{Soldagem:}

Nessa etapa, todas as peças foram medidas e cortadas e passadas para a soldagem das partes fixas.

\section{Lixamento:}

Nessa etapa foi feito acabamento final no corpo inteiro do braço Mecânico.

\section{Pintura:}

Nessa etapa o produto acabado recebe uma pintura de tinta que serve como proteção à oxidação.

\section{Teste:}

Os testes foram realizados na Associação por meio do acompanhamento de seus colaboradores pelos alunos, no ambiente que necessitava da sua utilização. Por meio de um teste com fixação do produto, foi possível observar que seria necessária uma modificação nas medidas da chapa de fixação da base, por motivos de trocas de caçamba que não se encontravam no local no momento do teste, e que tinha como características medidas diferenciadas.

Após as modificações os testes puderam ser retomados novamente no local, e o produto foi fixado para suspensão dos bags na altura desejada por meio de uma talha de corrente (é uma ferramenta constituída de roldanas e correntes, especialmente desenvolvida para facilitar o içamento de cargas pesadas).
Realização:

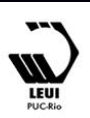




\section{$16^{\circ}$ \\ ERGODESIGN USIHC CINAHPA}

$16^{\circ}$ Ergodesign - Congresso Internacional de Ergonomia e Usabilidade de Interfaces Humano Tecnológica: Produto, Informações Ambientes Construídos e Transporte

$16^{\circ}$ USIHC - Congresso Internacional de Ergonomia e Usabilidade de Interfaces Humano Computador

CINAHPA | 2017 - Congresso Internacional de Ambientes Hipermídia para Aprendizagem.

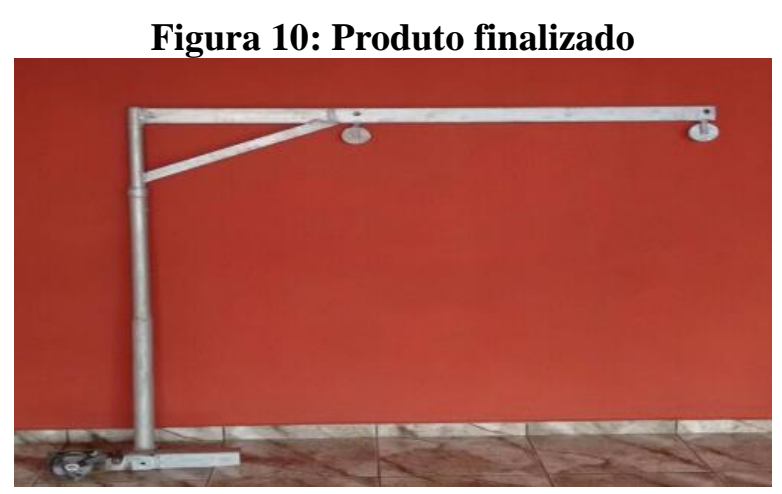

Fonte: Os autores (2016)

No desenvolvimento do produto não foram envolvidos encargos relacionados à mão de obra, devido ao fato de ter sido realizado pelos alunos do Curso de Gestão da Produção Industrial da Fatec Jahu.

Foram encontradas dificuldades na compra do material (especificamente, da talha de corrente) o que causou atrasos na elaboração do projeto.

Foram realizados testes durante duas semanas na Associação Recicla Jaú e os colaboradores deram o feedback sobre o braço mecânico. $\mathrm{O}$ produto foi utilizado durante aproximadamente sete meses, houve a quebra da base de apoio da travessa da caçamba aonde o Guindaste de elevação foi fixado. Após o reforço da base, foi colocado o produto na caçamba e assim retornado a sua utilização.

\section{Conclusões}

Neste projeto foi possível desenvolver o braço mecânico (guindaste) para atender a necessidade dos colaboradores da Associação Recicla Jaú, possibilitando praticidade e eliminação de esforços físicos. Os colaboradores da associação antes de ser instalado o guindaste nas operações de elevação dos bags, utilizava a força física, sendo que eram necessários dois trabalhadores para suspender o bag. Em relação ao esforço físico muitos colaboradores se lesionavam na realização de suas atividades na Associação Recicla Jaú. Após a instalação do guindaste para cada operação de elevação se utiliza um colaborador, em relação concepção do produto a sua ergonomia, se anulou o esforço físico.
No mês de Junho de 2015 o produto foi instalado no local e, após duas semanas, foram analisados os resultados por meio da avaliação dos colaboradores da associação. $\mathrm{O}$ produto foi considerado satisfatório e possibilitou a eliminação de grande parte dos esforços físicos excessivos que eram realizados, trazendo conforto e rapidez nas operações.

\section{Referências:}

AREASEG. "Norma Regulamentadora NR 17" consultado em 08/12/2016.

BACK, N. Metodologia de Projeto de Produtos Industrial. Rio de Janeiro: Guanabara Dois, 1983.

BAXTER, M. Projeto de Produto: Guia prático para o design de novos produtos. São Paulo. Blücher, 2000.

BAXTER, R.M. Projeto de produto: guia prático para o designer de novos produtos. $3^{\mathrm{a}} \mathrm{Ed}$. rev. São Paulo: Blucher, 2011.

\section{CUPANI, A. La pecularidad del conocimento} tecnológico. ScientiaeStudia, São Paulo, v.4, n.3, p.353-71, 2006.

FELIX, R. A. Z. Coleta seletiva em ambiente escolar. In: Revista eletrônica.

FILHO, D.C. Mestrado em Gestão Integrada de Organizações. Universidade do Estado da Bahia / Departamento de Ciências Humanas, Campos I Salvador (BA).

FILHO, G. J. Ergonomia do objeto: sistema técnico de leitura ergonômica. 2 ed. São Paulo: Escritura Editora, 2010.

IIDA. I. Ergonomia Projeto e Produção. $2^{\text {a }} \mathrm{Ed}$. rev. São Paulo: Blucher, 2005.

MORAES, D. Metaprojeto - o design de design. São Paulo: Editora Edgard Blücher, 2010.

Demag braços giratórios. Disponível em: <http://www.demagcranes.com.br/page 102724.html 